\title{
O fator econômico como propulsor da Ciência Jurídica.*
}

\author{
José Pinto Antunes \\ Professor catedrático de Direito Econômico \\ da Faculdade de Direito da Universidade \\ de São Paulo.
}

A Faculdade de Direito da Universidade de São Paulo está em festas para receber condignamente os eminentes advogados brasileiros.

Sabemos a que vêm VV. Ex.as, mas o agradecimento, que nos trazem, pela concessão dos nossos salões para as sessões solenes de abertura e encerramento do certame, coincide com o destino e a obrigação desta Casa de estar presente e participar dos movimentos nacionais quando, principalmente como nesta ocorrência, discute-se uma nova ordem jurídica para um país que se desenvolve econômicamente, em passadas de gigante.

A propósito, Ex. as, o Diretor, suprindo a sua humildade, recebe VV.Ex. ${ }^{\text {as }}$ nesta Sala, sob o patrocinio do Visconde São Leopoldo, onde a presença, hierática, dos grandes mestres desta Casa, recordam a participação continuada dos nossos juristas nesta obra, mais que centenária, de traçar e retraçar as normas jurídicas que os fatos novos, em sucessão contínua, vão pedindo à ciência dos jurisconsultos.

Somos nós, pois, que agradecemos o chamamento para participar, com o nosso acervo, nesta obra estrutural ao serviço da pátria comum, nesta semana que se ultima.

* Discurso proferido na abertura da IV Conferência da Ordem dos Advogados do Brasil, realizada no salão nobre desta Faculdade, de 26 a 30 de outubro de 1970 . 
Em verdade, em todos os tempos, o fator econômico constituíu a fôrça geradora de novas normas jurídicas e, continuadamente, o instrumento propulsor de uma ordem jurídica que se unifica e universaliza. A ciência jurídica se amplia e completa, assim, ao seu impacto.

No início desta história, já a extorsão fiscal dos colonos, ocasionando o êxodo para a cabeça do Império Romano, determinara relações sociais novas entre patrícios e plebeus, não previstas pelo seu velho direito e, então, pela ação do pretor peregrino, inspirado pela ciência dos jurisconsultos, novo direito foi se eleborando e uma nova ordem jurídica se estruturou para se ajustar aos novos e inusitados fatos. O jus gentium carregou-se, então, desta universalidade que já anunciava a ciência jurídica, e com a qual os romanos passaram a disciplinar as relações privadas dos povos de costumes os mais diversos, como acontece, ainda hoje, com o código civil japonês.

Prossegue o fator econômico na sua fôrça geratriz quando, na idade média, expande-se o comércio nas cidades italianas e o ato de intermediação não encontra, naquêle direito, a disciplina que necessita para sua vivência. São os próprios interessados que formulam as suas próprias normas de conduta, uma auto-disciplina de classe, fenômeno que vai-se repetindo na história do direito, onde uma norma social, elaborada pelos próprios interessados, vai se antecipando do posterior reconhecimento e formulação, pelo poder político da comunidade, de uma nova ordem jurídica ajustada aos novos fatos sociais gerados pelo desenvolvimento econômico.

"Ex facto oritur jus", já ensinavam os romanos e "até numa quadrilha de gatunos são necessárias normas que dividam o espólio das vítimas", diz Hugo Grotius, citando ARIstóteles.

Todo fato econômico é um ato jurígeno e o direito conseqüente, que se impõe, nasce, quase sempre, da própria convenção da sociedade carente da disciplina, antes que o 
Poder político ou o Estado o reconheça e o integre na sua ordem jurídica cogente. Trata-se da continuada elaboração da norma social em complemento necessário ao tardio direito legislado.

O Direito Comercial, o jus mercatorum da idade média, foi o fruto espontâneo desta sociedade de intermediadores, de corredores (corretores), que iam e vinham, na faina de lucrar, equilibrando produção e consumo, elaborando e estendendo os mercados. Pelas estradas, cobriam-se de poeira e dos melhores eram escolhidos os juízes, juízes pés de poeira, pies powders, para decidirem os desajustes sociais oriundos do intercâmbio comercial, até então desconhecido na sociedade e conseqüentemente do direito vigente. Elaborava-se, assim, ao impacto do novo fator econômico, o ato de comércio, um novo direito carregado de generalidade e conseqüente universalidade e que, devido a estas características, iria influir, até nossos dias, no aperfeiçoamento das normas de direito privado, elevando-as à categoria do científico, porque comuns a todos os povos, transmutadas, como foram, pela assinalada universalidade no espaço e no tempo. O Direito privado universalmente se unifica pela fôrça, ao mesmo tempo revolucionária e ordenadora, do fator econômico.

No século xix, continuando o nosso escorço histórico, no século xix continua a transformação jurídica, neste paralelismo, que vimos examinando, da expansão das relações sociais, concomitantemente com a necessidade da sua disciplina jurídica.

O capitalismo industrial, complementando o comercial da idade média, traz uma revolução nas relações entre os fatôres da produção. Ao artesão, titular dos instrumentos de produção, sucede o operário, escoteiro do capital que fica em mãos diversas. A emprêsa, unidade última da produção, elabora a nova combinação dos fatôres produtivos e o titular do trabalho, subordina-se ao do capital, pelo vínculo jurídico, o contrato individual do trabalho subordinado, 
forma inusitada de relação social que definirá o desenvolvimento econômico de então até os nossos dias.

O capitalismo privado traz o conflito de interêsses entre quem tem o capital, mas sem os meios de fazê-lo eficiente, pois a concorrência pede a redução continuada do custo da produção, dependente, por sua vez, das máquinas (capital), que mãos diversas detêm (capitalistas).

$O$ conflito dêstes novos interêsses desconhece o direito legislado. A luta de classe evidencia a deficiência apontada. A greve, os bracos cruzados dos operários, exprime a reação dos econômicamente subordinados. O Estado liberal, ausente por definição, ocasiona a solução pelos próprios interessados. E mais uma vez, na história do direito, encontra-se na auto-disciplina grupal a elaboração da norma jurídica social para solução do conflito para cuja solução não estava ainda o Estado aparelhado.

O contrato coletivo, a modo de um tratado de paz, pondo têrmo à greve, elaborava, ao mesmo tempo, o novo direito social, para disciplina das novas questóes, oriundas das novas relações criadas pela produção econômica por via da emprêsa.

Mas êste mesmo Direito social do trabalho que, avançando pelo século $\mathrm{xIX}$ afora, nos princípios do século $\mathrm{xx}$, marca e define as ordens jurídicas com o seu característico e que, mais ainda, com as "Cartas de Trabalho", postergando os direitos políticos, fundamentaram popularmente, as ditaduras fascistas, está com os seus dias contados pela falta do objeto que lhe é dia a dia retirado na revolução tecnológica das fábricas sem operários.

o Direito do Trabalho, como disciplina jurídica da subordinação empregatícia, perde o seu objeto, porque os escravos eletrônicos eliminam, cada vez mais, o pessoal subordinado à emprêsa.

É fato que a ordem juridica sofre os abalos profundos no capítulo, ainda incipiente, do setor público. Novamente se pergunta a quem devem pertencer os instrumentos de pro- 
dução quando, agora, mais do que antes, sua titulariedade ameaça os meios de sobrevivência dos sem capital, dos titulares exclusivos da fôrça de trabalho. O problema da socialização dos instrumentos de produção se repõe na liistória com gravidade inusitada, pois a máquina já está produzindo a própria máquina, neste desdobramento do fenômeno econômico que poderíamos chamar, à semelhança do biológico, da partenogênese mecânica.

A nossa profissão, senhores advogados, toma um sentido diverso, mais carregada de responsabilidade e mais exigente de ciência. Ao invés do patrocinador de causas, do advogado no forum, em debate judicial, a nova ordem econômica, estruturada em grandes empresas, trustes e cartéis, pede o conselho acertado para sua formação e desenvolvimento, a fim de que a sua ascensão econômica não seja desviada do econômico para o judicial, que é onus, não compensa, nada tem a ver com o lucro que a orienta e empolga e, muito ao contrário, impede a propaganda, a conquista dos mercados que se estendem e unificam.

Não há tempo para o judiciário no mundo dos negócios. o Direito Processual perde o seu porquê, pois é também cânone da economia moderna o preceito da prudência ensinada pela sabedoria popular: "mais vale um mau acôrdo que uma boa demanda.. " O bom conselho anula a hipotética disputa. No forum, já rareiam os grandes feitos..

A nossa profissão se requinta, sem dúvida, a modo da Roma antiga, onde o povo amanhecia às portas dos jurisconsultos, em demanda dos conselhos para prevenção dos conflitos e a paz, que fluía dos seus aforismas, dava-lhes a honraria de eminentes homens públicos.

o Direito preventivo prefere ao repressivo.

Mas o excesso da prevenção toma conta, também, dos responsáveis pela ordem pública. A doutrina da segurança nacional, para prevenir e combater o terror, contrasta, hoje, com a medida preventiva em prol dos direitos individuais que, desde 1215 , constituia a maior conquista da dignidade 
humana traduzida em norma jurídica. O coletivo e o individual chocam-se, assim, na técnica da proteção e cabe à ciência do direito, como um novo problema, a solução conciliatória dos dois interêsses, igualmente, necessitantes de adequada proteção.

É no campo do Direito Constitucional onde se embatem as nossas concepções de reformulação da ordem jurídica em busca da melhor justiça. O Direito das gentes empalma hoje a responsabilidade de garantir os Direitos individuais universalmente porque, na esfera nacional, a sua garantia demonstrou ser precária. A doutrina da auto-determinação dos povos, sustentada enfàticamente pelas ditaduras, revelou a insuficiência da proteção da dignidade humana pela ordem jurídica nacional. Os operários, pela parte XIII do Tratado de Versalhes, em 1919, já tiveram a intuição, em relação aos seus direitos, de que sòmente a garantia internacional daria eficiência às suas conquistas. Hoje são os direitos do homem e do cidadão que pedem ao Direito Internacional Público a última palavra no amparo às continuadas ameaças ou ofensas às suas garantias. Ao Direito das gentes cabe, assim, a guarda do capítulo primeiro da ordem jurídica, pois os demais constituem, simplesmente, a mecânica da sua realização.

\section{Senhores advogados.}

Desculpem-me a impertinência. O professor traz o hábito do cachimbo e faz preleção sem querer e mesmo sem propósito, mas, no caso, teve a finalidade de prolongar a presença ilustre de VV. Ex. ${ }^{\text {as }}$ nesta Casa que foi e deseja que seja sempre o cadinho onde se funde o ouro da ciência jurídica, traçando e retraçando o sistema legal que assegura a todos os brasileiros o progresso, mas com a dignidade individual assegurada pelo Estado de Direito.

Muito obrigado pela honrosa presença de VV. Ex. as 